\title{
PERÍODOS DE CONVIVÊNCIA DE PLANTAS DANINHAS NO FEIJÃO-CAUPI
}

\section{Carlos Zacarias Joaquim Júnior'; Marcia Joaquim da Silva²; Nelito Nhanca N'Bali ${ }^{3}$ Inácio João Barbosa ${ }^{4}$; Lamine Sanó ${ }^{5}$; Edson Lopes Cardoso ${ }^{6}$; Nancy da Costa ${ }^{7}$; Edmilson Ndami Lopes Cardoso ${ }^{8}$; Emanuel D' Araújo Ribeiro de Ceita'; Luís Gustavo Chaves da Silva ${ }^{10}$}

${ }^{1}$ Engenheiro Agrônomo, Unesp, Jaboticabal, São Paulo, ${ }^{2}$ Engenheira Agrônoma, Unilab, Redenção, Ceará.

${ }^{3}$ Engenheiro Agrônomo, Udesc, Lages, Santa Catarina, ${ }^{4}$ Engenheiro Agrônomo, Unesp, Jaboticabal, São Paulo, ${ }^{5}$ Engenheiro Agrônomo, Udesc, Lages, Santa Catarina, ${ }^{6}$ Engenheiro Agrônomo, Unesp, Jaboticabal, São Paulo, ${ }^{7}$ Engenheira Agrônoma, Udesc, Lages, Santa Catarina, ${ }^{8}$ Engenheiro Agrônomo, UFRS, Porto Alegre, Rio Grande do Sul, ${ }^{9}$ Engenheiro Agrônomo, Unesp, Jaboticabal, São Paulo, ${ }^{10}$ Engenheiro Agrônomo, Professor, Unilab, Redenção, Ceará.

DOI: 10.47094/ICONNECA.2021/4

\section{RESUMO}

Um dos maiores problemas encontrados na produção de feijão-caupi são as plantas daninhas, devido a competição e interferência causada por estas plantas. $\mathrm{O}$ estudo visa determinar os períodos de interferência de plantas daninhas com a cultura do feijão-caupi. O estudo foi realizado em delineamento de blocos casualizados, com dez tratamentos e quatro repetições. A avaliação da produtividade foi realizada aos 80 dias após a emergência. O PAI encontrado foi de 8 DAE, PTPI de 53 DAE e PCPI de 45 DAE. A produtividade máxima no controle foi de $3.500 \mathrm{~kg} \mathrm{ha}^{1}$ e convívio foi de $2.294 \mathrm{~kg} \mathrm{ha}{ }^{1}$. O rendimento da cultura foi reduzido em $73,5 \%$, o que permite afirmar que a cultura não deve conviver com as plantas daninhas durante o período crítico de competição.

PALAVRAS-CHAVES: Vigna unguiculata. Interferência. Matocompetição.

ÁREA TEMÁTICA: Outros.

\section{INTRODUÇÃO}

O feijão-caupi (Vigna unguiculata (L.) Walp., também conhecido como feijão macassar, é uma das leguminosas com maior importância econômica para algumas regiões do Brasil, constituindose como uma das mais importantes fontes proteicas na alimentação da população rural (BEZERRA, et al., 2014).

O valor nutritivo do alimento desta cultura é considerado alto, pois apresenta alguns ingredientes essenciais como aminoácidos e proteínas, por isso é mais utilizado para a produção de grãos (secos ou verdes), para fins de consumo humano (LIMA, 2015). 
O Brasil situa-se nos países com maior produção e consumo de feijão-caupi, uma vez a produtividade média do país em grãos está em torno de $525 \mathrm{~kg}_{\text {ha- }}{ }^{1}$ e produção de 687,4 mil toneladas (CONAB, 2021).

Um dos fatores que limitam o rendimento da cultura é a interferência causada pela comunidade infestante em áreas de cultivo, isso culmina também com a baixa produção, por razões da competição que se estabelece ao longo do crescimento e desenvolvimento da cultura (LACERDA, et al., 2020). Sendo assim, é muito importante conhecer as épocas e dos períodos de convivência entre a cultura e as comunidades infestantes, uma vez que, quanto maior o período de convivência, maior será a interferência e o rendimento (PITELLI \& PITELLI, 2008).

O objetivo deste trabalho é de determinar o período anterior a interferência (PAI), período total de prevenção à interferência (PTPI) e o período crítico de prevenção à interferência (PCPI), com e sem interferência da comunidade infestante na cultura do feijão-caupi.

\section{MATERIAL E MÉTODOS}

O experimento foi realizado em 2019 na área experimental do Campus das Auroras - Unilab, Redenção-CE, em delineamento de blocos casualizados, com dez tratamentos e quatro repetições. Os tratamentos foram divididos em duas parcelas (parcela subdividida), constituídos de períodos de controle (no limpo) ou convivência (no mato) das plantas daninhas com a cultura.

Os períodos de controle em DAE (dias após a emergência) foram em intervalos de 20 dias, sendo dessa forma: 0 DAE; 0 à 20 DAE; 0 à 40 DAE; 0 à $60 \mathrm{DAE}$; 0 à 80 DAE que corresponde ao período de colheita. Foi utilizada a variedade crioula, que possui um ciclo de 71-90 dias, sendo considerado médio-precoce, de acordo com (EMBRAPA, 2002), provenientes do Sítio Nova Assunção de Aracoiaba-CE. O espaçamento foi de 0,50 entre fileiras e 0,25 entre plantas.

Em cada cova de $4 \mathrm{~cm}$ de profundidade, foram colocadas 4 sementes. A densidade foi de 16 plantas por cada parcela. O desbaste foi realizado 15 dias após a semeadura. A irrigação é feita com regadores manuais em dois períodos diários (manhã e tarde), em uma lâmina de 42 L diário, por cada parcela.

A produtividade (PRD) de grãos, foi estimada com base na coleta de cinco plantas da área útil de cada parcela. A coleta das plantas amostradas foi feita aos 80 dias após a emergência (DAE), quando a cultura apresentou folhas em senescência e as vagens com coloração palha acima de 75\%. Os dados foram submetidos a análise de regressão linear por grupos de tratamentos. 


\section{RESULTADOS E DISCUSSÃO}

Considerando-se a perda de $10 \%$ na produtividade da cultura, verificou-se que a produção do feijão caupi começou a sofrer interferência das plantas daninhas a partir dos 7 DAE, o que é denominado como PAI. O valor mostra que de 0-7 dias após a emergência, a cultura pode conviver com as plantas daninhas sem que haja interferência em qualquer das características da planta ou mesmo redução significativa na produtividade. Este valor do PAI (7 DAE) pode ser determinado pela baixa densidade de plantas daninhas nos estádios iniciais de desenvolvimento da cultura. Os fluxos iniciais de germinação e desenvolvimento das plantas daninhas, que ocorrem logo após a semeadura e a emergência da cultura, são normalmente os de menor intensidade, não muito importantes em termos da interferência inicial, uma vez que não impõem à cultura uma situação de restrição de recursos de competição.

O PTPI foi de 69 DAE, indicando que a partir deste o período a cultura do feijão-caupi pode conviver com as plantas daninhas (gráfico 1). O período crítico de prevenção à interferência (PCPI) é estimado pelo intervalo entre o PAI e o PTPI, sendo assim, o PCPI é de 62 DAE, ou seja, o intervalo de 7 à 69 DAE. No entanto, é o período em que as medidas de controle devem ser efetivadas, pois as plantas daninhas que emergirem nesse intervalo causaram danos significativos na produtividade. O PCPI foi bastante extenso, isso deve-se a maior espaçamento utilizado na semeadura e consequentemente a menor densidade de plantas de feijão-caupi nas parcelas. Sendo assim, este intervalo de tempo pode ser minimizado pela redução no espaçamento, permitindo dessa forma, a maior densidade da cultura.

A produtividade da cultura de feijão-caupi no convívio com as plantas daninhas no período de 0 DAE foi superior à produtividade da cultura quando estas foram controladas. Para o manejo controle de plantas daninhas nos períodos 20, 40, 60 e 80 DAE, houve maior produtividade da cultura em relação aos mesmos períodos avaliados no manejo em convivência. Rendimento de grãos máximo, obtido pelos tratamentos que não foram afetados pela interferência das plantas daninhas, é de aproximadamente $3.500 \mathrm{~kg} \mathrm{ha-}{ }^{1}$, enquanto que $2.294 \mathrm{~kg} \mathrm{ha}^{1}$ foi o rendimento máximo nos tratamentos em convivência com a comunidade infestante. A produtividade foi superior ao encontrado em outras pesquisas, isso pode ser o fato de a área experimental ser nova e nunca antes cultivado.

O resultado do PAI alcançado neste trabalho está próximo do encontrado por Freitas et al. (2009), que determinaram para o feijão-caupi o PAI até os 11 DAE. E abaixo ao resultado encontrado por Salgado et al. (2007) observaram para a cultura do feijão carioca que o PAI ocorreu até os 17 DAE da cultura. 
Gráfico 1: Rendimento de grãos de feijão-caupi em função dos períodos de controle (no limpo) e convivência (no mato) com as plantas daninhas. UNILAB, Redenção-CE,2019.

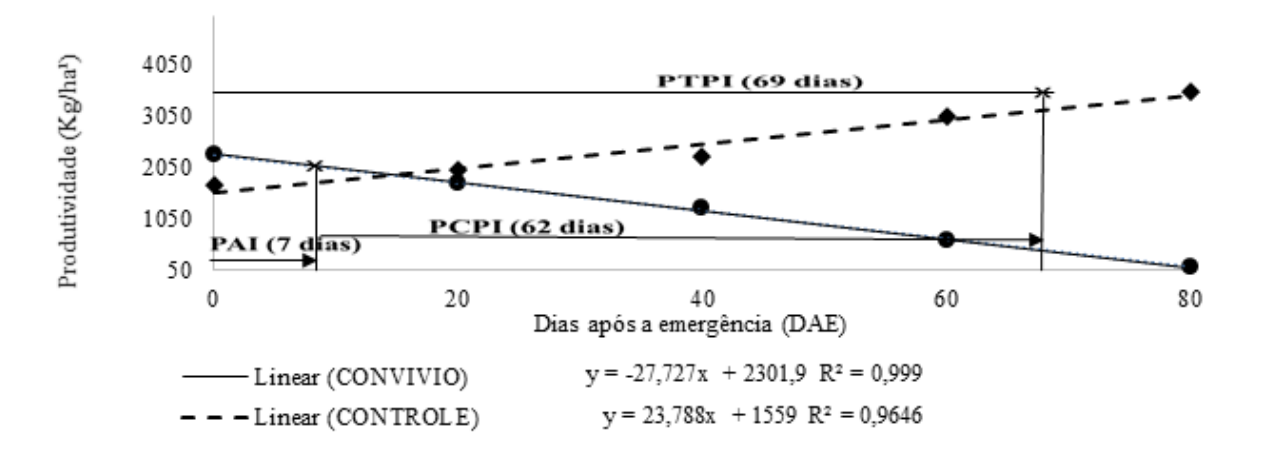

Fonte: Joaquim Jr., 2019.

Os resultados de estudos recentes alcançados na determinação dos períodos de interferencia PAI, PTPI e PCPI estão próximos os de Corrêa et al (2015), com PAI de 8 dias após a emergência (DAE), o PTPI de 53 DAE e o PCPI de 45 DAE, com a redução no rendimento de 46\%. Por tanto, este estudo não corrobora o de Castro et al (2019), onde foi encontrado o PAI de 9 DAE, PTPI de 41 DAE e o PCPI de 32 DAE, a redução no rendimento foi de 39,8\%. Nos resultados encontrados no estudo feito por Lacerda et al (2020), onde observou-se que o PAI foi de 20 DAE, PTPI de 32 DAE e o PCPI de 12 DAE e uma redução no rendimento de $73,5 \%$.

\section{CONCLUSÃO}

Com os resultados alcançados neste trabalho, conclui-se que o período crítico encontrado foi de 62 dias após a emergência, ou seja, o controle das plantas daninhas na cultura do feijãocaupi deve ser realizado a partir do PAI 7 DAE até aos 69 DAE da cultura, para evitar com que a competição da cultura com as plantas daninhas não proporcione queda na produtividade da cultura e consequente perda econômica aos produtores. A partir deste intervalo (PCPI), devem ser adotadas medidas cabíveis de manejo da comunidade infestante para evitar prejuízos.

A condução da cultura do feijão-caupi no convívio (mato) com as plantas daninhas, proporcionou a redução da produtividade da cultura de 70\% em relação ao controle (limpo), ou seja, quanto maior o convívio da cultura com a comunidade infestante, maior é a interferência e redução de produtividade. 


\section{PRINCIPAIS REFERÊNCIAS}

BEZERRA, M. A. F.; OLIVEIRA, F. A.; BEZERRA, F. T. C.; PEREIRA, W. E.; SILVA, S. A. Cultivo de Feijão-Caupi em Latossolos sob o Efeito Residual da Adubação Fosfatada. Revista Caatinga, v. 27, n. 1, p. 109-115, 2014.

CASTRO, T. S.; ROCHA, P. R. R.; BARRETO, G. F.; MAIA, S. S.; ALBUQUERQUE, J. A.A.; ALVES, J. M. A. Weed Interference in Semi-erect and Semi-prostate Cowpea Cultivars. Planta Daninha, v. 37, n. e019196146, p. 1-9, 2019.

CORRÊA, M. J. P.; ALVES, G. L.; ROCHA, L. G. F.; SILVA, M. R. M. Períodos de Interferência de Plantas Daninhas na Cultura do Feijão-Caupi. Revista de Ciências Agroambientais, v. 13, n. 2, p. 50-56, 2015.

LACERDA, M. L.; ASPIAZÚ, I.; CARVALHO, A. J.; SILVA, A. F.; FERREIRA, E. A.; SOUZA, A. A.; CAMPOS, M. L.; BRITO, C. F. B. Periods of Weed Interference in Cowpea Crop in the SemiArid of Minas Gerais, Brazil. Revista Brasileirade Ciencias Agrarias, v. 15, n. 6749, p. 1-6, 2020. 